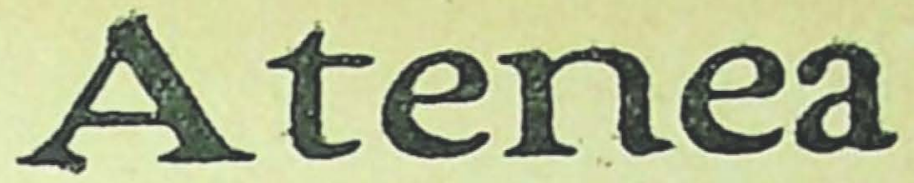

REVISTA MENSUAL DE CIENCIAS, LETRAS BELLAS ARTES. PUBLICADA POR LA UNIVERSIDAD DE CONCEPCION.

Año VII - Santiago, Junio de 1930 - Núm. 64

Ernesto Glaeser

\title{
LA POSICION DEL ESCRITOR EN IA ACTUALIDAD
}

F NTRE los libros alemanes relativos a la gran guerra y que han aparecido en los dos últimos años, traducidos en casi todos los idiomas, Los que teníamos doce años de Ernesto Glaeser es, con Guerra de Ludwig Renn y el célebre Sin novedad en el frente de Remarque, el que ha tenido más éxito. Es necesario hacer notar que, entre los tres, es el de mayores valores literarios y el que nos revela a un escritor de porvenir. Remarque y Renn han alcanzado el triunfo porque sus libros correspondian a una tendencia espiritua, unánime. Aprovecharon una oportunidad porque; en realidad, sus libros no ofrecen nada realmente nuevo. Glaeser, en cambio, representa una nueva generación que habla y que aun no ha terminado de hablar.

Glaeser nació en una pequeña aldea de la Renania, cerca de Maguncia, el año 1902. Su padre era juez. Desde

Atenea.-25 
su infancia conoció las interioridades de la burguesía burocrática imperial. Llegó la guerra: el niño, de 12 a 16 años, sufrió en elliceo yen la pequeña aldea todos los contratiempos. $Y$ son esos contratiempos de la guerra, que chocan contra la mentalidad de la nación, los que describe en su libro. Derrumbamiento de las ideas imperiales, trastorno de las costumbres, todo lo que produjo la guerra en la población civil de la Alemania acosada lo ha traducido Glaeser en la fresca visión de un adolescente, pero con la conciencia de un hombre que sabe prescindir, entre sus recuerdos personales, de la anécdota para no subrayar más que el hecho psicológico de importancia histórica.... Su libro contiene, así, una aplicación de las ideas que expone en el artículo siguiente, ideas características del estado actual de evolución social y espiritual en que se encuentra Alemania.

Actualmente Glaeser prepara una nueva novela: Wiederaufbau (Reconstrucción) en la que describe la revolución de 1919, la reconstrucción económica del país y la lucha por la consolidación de la República. Al leer su artículo pudiera creerse que sus teorías justifican su arte $y$ que su tesis reduce la potencia de vida que se traduce en su última obra. Quien le conozca y sepa con qué pasión se entrega a la observación de la vida individual no manifestará esa creencia y le otorgará su confianza.

\section{$\star$}

Dos ideas se contraponen al estudiar la misión propia del escritor en la hora presente. Una, que nosotros llamaremos romántica, quiere que el escritor se independice de las luchas que agitan a la comunidad política-social, entendiendo que debe permanecer al margen de las discusiones y conflictos de su tiempo, viendu en él el representante de los valores eternos y funda- 
mentales de la humanidad, que se mantienęn a través de todas las épocas, prohibiéndole la intervención en las luchas que destacan el perfil humano de la época en que vive, reclamando de él un abstencionismo de partido, la neutralidad política, un arte alejado de la polémica social.

La otra tendencia, a la que pertenece la mayor parte de los revolucionarios, reclama al escritor, lo induce a tomar posición y a luchar. Le pide que defienda los valores humanos contra las fuerzas que los amenazan. Exige su intervención en las luchas sociales, en los conflictos ideológicos mundiales. Llega hasta exigirle que sirva a un partido, un grupo, una clase políticamente activa. Y en este caso el escritor ha de interpretar el estado psicológico y fisiológico de importantes grupos de la humanidad, traduciendo sus caracteres y su situación material, social y espiritual.

Ambas tendencias combaten ardorosamente hoy día. Del resultado de esa lucha dependerá el contenido de la literatura alemana en los próximos cincuenta años.

\section{$\hat{\imath}$}

Nos encontramos, hoy día, en Alemania, frente a esta alternativa: queremos una literatura neutral o una literatura activa, que tome una actitud crítica ante la situación del hombre y de las instituciones sociales. ¿Queremos escribir para describir o para cambiar? ¿La literatura debe traducir sin ambajes las luchas nacionales, entrevistas en sus perspectivas humanas, o bien va a regresar a la antigua tradición del arte por el arte?

He aquí la síntesis esquemática, las bases del problema que quisiera examinar. Por de pronto hay que 
conocer la situación del hombre en nuestra época, puesto que el hombre es el material con que trabaja el escritor. ¿Comparativamente a épocas anteriores se ha modificado esta situación?

Sí, se ha modificado. Hemos salido del individualismo del siglo XIX para entrar en el colectivismo del gran capitalismo. Y el progreso de depreciación del individuo no es solamente de orden económico. Es también un fenómeno espiritual. A la rebelión individual ha susbtituido la lucha de clases, la revolución materialista. La invisible sociedad anónima ha reemplazado al pequeño propietario de carne y hueso. En vez del solo hombre, el grupo; la organización en lugar del indiyiduo. Los hombres han llegado a ser casi imperceptibles, sus ideas han sido estandarizadas según las leyes de su situación social. El hombre aislado ya no es, como en el pasado, una personalidad que se forma a sí misma sino la expresión de un grupo. Ya no es dueño de sus ideas sino servidor de las ideas de un grupo. Su existencia privada está sometida a la potencia colectiva de una clase, de una organización. Poco importa que esta sea nacional, del proletariado universal, de la Iglesia Católica o del gran capitalismo americano. Basta comprobar este hecho:hoy día la mayoría de los hombres vive según las leyes espirituales y económicas colectivas y el pensamiento individual se debilita. Esto se ve hasta en el sport y en la forma más primitiva de colectivismo, el nacionalismo. Este fenómeno se manifiesta en todo. El retroceso del protestantismo y la decadencia del liberalismo, ambos de esencia individualista, se relacionan.

Como escritores, ya no nos encontramos frente a hombres aislados, individuos concentrados en sí mismos. Nos hallamos delante de grupos de hombres. No estamos frente al individualismo, sino frente a los miembros de las organizaciones. El hombre tomado aisladamente ha dejado de ser una materia artística en 
la medida en que su pensamiento y su vida están sometidos a la vida y pensamientos de un grupo.

Un nuevo tipo humano se ha formado con el retroceso de la iniciativa privada. No quiero decir que ese tipo sea puramente utilitarista, superficial, reducido a dos dimensiones-porque algunos grupos se mueven a un nivel espiritual que el individuo no podría esperar jamás-. Frente a este tipo nuevo, la literatura no puede ver lo particular, sino buscar lo general. Para ser verídico, el escritor debe descubrir la estructura de la vida y librarla de lo excepcional para traducir solamente lo típico.

Si quiero presentar a un pequeño empleado no podría hacerlo prescindiendo de su profesión. Para penetrar en su psicología necesito pasar por su especialidad, penetrarme también de ésta. Si deseara delinear la personalidad de un hombre de negocios, no llegaría a nada describiendo sus características físicas, mostrando sus preferencias por la carne o las legumbres, por las mujeres rubias o las morenas. Tendría que mostrar el hombre trabajando, asido por las complicaciones de su profesión, en sus relaciones con las leyes del gran capitalismo. Entonces podría descubrir su psicología, porque sus caracteres generales son determinados por los fundamentos del trabajo que el hombre ejecuta. Por ejemplo, es posible que alguien haya amado en su juventud a los animales y que sea al presente presidente del Consejo de Adminstración de una sociedad que explote un matadero. Si importa la mercadería que vende, es la venta lo que le interesa. Los métodos de venta tendrán mayor influencia sobre su carácter que la mercadería. Debe vender con beneficio: es la ley del grupo. No debe pensar en lo que vende, sino en la utilidad. Traduce un sistema. Representar ese hombre es, en consecuencia, representar el sistema. Desaparece como persona privada, no queda de él más que la tendencia del grupo a que pertenece. 
Este ejemplo vale hoy día para la mayoría de los hombres. Cada cual piensa conforme a las leyes de un grupo. Tomemos otra categoría: un juez. Si tenemos de representarlo ¿qué debemos conocer de él? El Código. Porque un juez sin Código no es un juez, sino una persona privada que no nos interesa. Así como un juez que se rebela contra el Código no puede ser representado más que en funciones de tal, porque la ley domina todos sus pensamientos aun en las horas de descanso. Del contacto constante con la ley nacen las formas de su psicología. Su pensamiento está sometido al grupo en ese caso, a la clase dominante que usa el Código como instrumento de dominación.

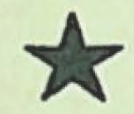

En los comienzos del siglo XIX era posible para un individuo vivir al margen de su grupo, fuera de su profesión. El Estado y las agrupaciones organizadas en su clase no tenían una potencia económica suficiente como para someter enteramente al individuo. El oficio y las clases constituidas no determinaban todavía la psicología del hombre. Entonces no estaba la vida tan reciamente ligada a una serie de leyes económicas que constituyen su objeto y contenido. El industrialismo al evolucionar hacia el gran capitalismo ha reducido al individuo al papel de empleado. La vida privada ha llegado a ser un instante de reposo mezquinamente medido entre dos jornadas de labor. El pensamiento individual se ha transformado en colectivo. No hay muchos hombres que sean tan libres como para poder representarlos fuera de la profesión que los une a ura clase. Nadie es tan fuerte como para establecer una separación entre su pensamiento y su situación eco- 
nómica ni para eludir su pensamiento a la influencia de esta situación. Cada cual es arrastrado por el rápido proceso de racionalización y de mecanización que invade al mundo. La libertad del individuo aislado cede lugar a la sumisión, a la ideología del grupo.

Henos aquí ante un punto decisivo de la evolución de nuestra época. Si subsiste en el hombre una tragedia en el sentido burgués, liberal de la palabra, es el combate silencioso y desesperado del hombre para la salvaguardia de su libertad individual en un mundo mecanizado. La lucha, en suma, del protestantismo, de la responsabilidad individual ante Dios y las leyes eternas. Y esta lucha, que es un hecho hoy día, conducirá al triunfo del colectivismo. Prácticamente la solución se ha vislumbrado en Rusia, en Italia y en América, mientras que la batalla continúa en Alemania y Francia. Pero no hay mayores esperanzas para éstos porque ambos países están amarrados por fuerzas económicas poderosísimas, cuyas leyes se imponen absolutamente y se han asentado en las jóvenes generaciones.

Esta evolución es un hecho histórico. Son vanas las lamentaciones. Mi objeto es ver y recuperar lo más posible; lo que no quiere decir que me contente con la simple comprobación de esto. Debemos considerarnos ante una evolución que no está en nuestra mano detener y en la corriente misma de esta evolución debemos determinar la posición y los deberes del escritor.

Los individualistas acostumbrados a considerar el arte como una actividad puramente subjetiva han concretado la cuestión: ¿tiene todavía sentido el arte en esta época racionalizada? No está demasiado lejana la época en que el escritor encantaba al lector por medio de conflictos psicológicos sin relación con su existencia. La literatura permanecía al margen de la vida pública porque ésta no dominaba enteramente la existencia 
del hombre. El mismo proletariado reclamaba obras que no se identificaban con su propia vida. Los trabajadores organizados, médula de la clase obrera, aunque comenzaban a pensar colectivamente, habían seguido la misma tendencia. Este hecho es sintomático de una época en que el pensamiento permanecía siendo individual y que quería reglamentar la suerte de las masas por medios individualistas, por medidas de previsión, de humanidad, de aburguesamiento del proletariado.

Tal concepto ha debido capitular en vista de las circunstancias. La guerra ha destruido el individualismo. Sus bases económicas se han revelado hoy día. Ha conducido a la racionalización, a la acumulación del capital en otro continente, a la trustificación del mundo. Amenazado en su existencia, el capital privado ha llegado a ser gran capitalismo, ha adoptado los métodos de organización del proletariado avant-guerre, ha tomado en cuenta la solidaridad y ha adoptado el colectivismo, se ha racionalizado echando por la borda al individualismo.

En esta situación, ¿cuál ha de ser la actitud del escritor?

Desde hace diez años la literatura experimenta sin cesar. Se pasa de una tendencia a otra. Estamos sobre un terreno movedizo, como en toda crișis social. Se crean escuelas que se dividen, doctrinas que se socavan. Un trabajo serio, una clara visión de la época, una justa apreciación de ella parecen imposibles. Arrastrados en este paso de lo individual a lo colectivo, hemos perdido la inspiración. Los escritores modernos, los que procuran percibir el signo de su tiempo, fracasan porque la sociedad en que viven se encuentra en estado de transición. Y los escritores que se sitúan únicamente en el terreno del individualismo, como Tomás Mann y Wassermann, alcanzan mucho más éxito porque se apoyan en algo neto: la humanidad burguesa 
y su centro, el individuo. Cuidémonos de no ver en ello un retroceso. Una profunda brecha se ha abierto en la literatura de ayer: los libros de guerra, distantes de todo refinamiento de estilo, que afrontan el trastorno del pensamiento individual en medio de la más decisiva circunstancia del siglo. ¿De qué proviene el éxito espontáneo de los libros de guerra? ¿De una nueva tendencia artística, de la revelación de nuevos talentos? No. Significan el reconocimiento de un nuevo estado de espíritu, contenido en un suceso del que nadie ha podido prescindir. Por primera vez, por medio de los libros de guerra, el pensamiento colectivo, bajo una forma popular, ha iluminado. No es que se amen esos libros por la evocación de la guerra, que gustaría recordar en aborrecible horror o en su exaltacio heroísmo, sino porque ellos traducen la existencia colectiva en medio de una tragedia. En Agosto de 1914 todos partían con la gran alegría de salir de su aislamiento individual y fundirse en la colectividad nacional. Si la gran comunidad social no se ha realizado, si, por el contrario, la guerra ha acentuado los antagonismos de clase, no es menos cierto que desde entonces el valor individual del hombre tiende a aminorarse y que la necesidad de leyes económicas ha reafirmado la dominación de grupos y clases sobre los individuos. En todos los campos reina hoy día el colectivișmo.

El escritor presencia este fenómeno como un vigilante observador. Si se desentiende de él pierde de vista el objeto de su investigación: el individuo sometido al pensamiento de un grupo. El grupo, no el individuo, debe ser el punto de partida para su creación. A ello lo obligan las circunstancias. Debe entonces adoptar una posición. Debe conocer la estructura de las cosas que quiere repressentar. Ya no puede entregarse simplemente a su fantasía: tiene que pensar. Debe conocer la sociedad. Esta le exige, no alegorías poéticas, sino obra 
basadas en sólidos conocimientos. No ha de temer el hacerse portavoz, conciencia de la sociedad.

El escritor debe conocer las grandes leyes de la economía y su acción sobre la estructura espiritual de los hombres. El hombre de su tiempo determinado por los conceptos del grupo al cual pertenece y las leyes económicas que sufre, debe considerarlos el escritor como representación de su grupo social. Hoy, que todo es confuso, el deber del escritor es ser claro. Debe traducir lo que es. Debe asir todas las perspectivas de la época. Y esto no podrá hacerlo sino por medio del conocimiento de la estructura de su tiempo, el conocimiento de las fuerzas colectivas que se oponen y el renunciamiento al sueño de libertad individual.

Exclusivo para Atenea en Chile. (Traducción de F. Ortúzar Vial.) 